CIC. Cuadernos de Información y Comunicación ISSN: 1135-7991

https://dx.doi.org/10.5209/ciyc.65773

\title{
El nuevo ecosistema informativo en Córdoba: un análisis a partir del caso del diario Día a Día
}

\author{
Libera Guzzi ${ }^{1}$
}

Recibido: 18 de octubre de 2018 / Aceptado: 25 de mayo de 2019

Resumen. Este trabajo se propone analizar algunos impactos que la nueva cultura digital tiene en la práctica profesional del periodismo en el ámbito local, a partir del estudio de un caso: el del diario Día a Día, que se editó en la ciudad de Córdoba (Argentina) entre 2004 y 2017. El objetivo es dar cuenta, en virtud de los datos recogidos a través de observaciones etnográficas y entrevistas semiestructuradas a algunos periodistas, del modo en que se han transformado las formas de construcción de la noticia. A partir del análisis realizado se constata la coexistencia de políticas editoriales y criterios de noticiabilidad distintos para el medio impreso y para el medio digital, y la vigencia de lógicas de tratamiento de la información tradicionales en lo que refiere a ciertos tópicos en los que históricamente el periodismo ha organizado y clasificado a los hechos de actualidad durante su etapa industrial.

Palabras clave: Rutinas periodísticas, convergencia, noticia, Córdoba.

\section{[en] The New Informative Ecosystem at Cordoba: an Analysis with the case of the Dia a Dia Journal}

\begin{abstract}
This work aims to analyze some impacts of the new digital culture on professional practice of journalism at local level, based on a case study: the "Día a Día" newspaper, which was published in Cordoba city (Argentina) between 2004 and 2017. The purpose is to show, based on the data collected through ethnographic observations and semi-structured interviews, the way in which the construction of the news has been transformed. After the analysis, we identify the coexistence of different editorial policies and newsworthiness criteria for the printed media and the digital media, as well as the validity of traditional information treatment logics as regards the topics around which historically it has been organized and classified current events in journalism during its industrial stage.
\end{abstract}

Keywords: News routines, Convergence, News, Córdoba.

Sumario. 1. Introducción: nuevos modos de informar y de informarse. 2. Aspectos metodológicos y la elección del caso de análisis. 3. Resultados: ¿fin del periodismo industrial?. 4. A modo de cierre: ¿un nuevo ecosistema informativo en Córdoba?. 5. Referencias bibliográficas.

Cómo citar: Guzzi, L. (2019). El nuevo ecosistema informativo en Córdoba: un análisis a partir del caso del diario Día a Día, en CIC. Cuadernos de Información y Comunicación 27, 47-60.

1 Programa de Estudios de Comunicación y Ciudadanía- Centro de Estudios Avanzados - Facultad de Ciencias Sociales - Universidad Nacional de Córdoba. 


\section{Introducción: nuevos modos de informar y de informarse}

Son muchos los significantes a partir de los cuales, en los debates públicos actuales, se caracterizan distintos aspectos de la sociedad contemporánea, constituida ella misma en objeto de denominaciones diversas, tales como sociedad red, sociedad del conocimiento, sociedad informacional, entre otras.

Sin embargo, una categoría en particular predomina en los discursos académicos, políticos y mediáticos: la de convergencia. Si bien inicialmente este concepto refería al desarrollo y aplicación integrados de tecnologías, su alcance se ha extendido hasta designar una serie de transformaciones en las formas de producción y organización, en las rutinas de trabajo, en las modalidades de distribución y comercialización, y en las lógicas de consumo propias del sector infocomunicacional.

En ese contexto, la idea de que asistimos a la configuración de un nuevo ecosistema informativo y mediático (Aguado y Martínez, 2008; Salaverría y Negredo, 2008; Jenkins, 2008; Limia Fernández, López García y Pereira Fariña, 2010; Canavilhas, 2012; Díaz Nosty, 2013; entre otros) se sustenta en las transformaciones que, en principio, hoy se estarían produciendo en tres dimensiones fundamentales del sistema de medios masivos de comunicación: en primer lugar, en la estructuración económica y empresarial del sector infocomunicacional y su relevancia en la economía global; en segundo lugar, en los modos de consumo de información y contenidos por parte de las audiencias y los usuarios, de la mano de los elevados niveles de penetración de los servicios de internet fija o móvil en la población; y en tercer lugar, en las lógicas del ámbito profesional en todo el sector, especialmente en la producción de noticias.

Si bien se trata de un proceso que se encuentra en pleno desarrollo, y muchas veces las conceptualizaciones ofrecidas no se basan en análisis empíricos, ciertos datos ilustran algunas de las mutaciones en curso.

Respecto al primer punto, los nuevos entornos digitales han puesto en crisis los modelos de negocios en torno a los cuales los medios de comunicación tradicionales se organizaron desde el proceso de su industrialización, a fines del siglo XIX (Almirón y Segovia, 2012; Campos Freire, 2011; Díaz Nosty, 2013; entre otros). Un informe de la consultora IPG Mediabrands reveló, por ejemplo, que en 2017 la inversión en publicidad a nivel global en medios digitales creció hasta concentrar el $41 \%$ de la inversión total, superando a la de la televisión. Además, el informe indica que la tendencia estimada para los próximos años es un aumento de inversión publicitaria en medios on line junto a una variación negativa de la inversión en los medios off line, al punto de que para 2020 los medios digitales podrían llegar a concentrar más del $50 \%$ del mercado publicitario global ${ }^{2}$. Además, toda la inversión en publicidad en entornos digitales se distribuye de manera desigual entre plataformas de redes sociales, buscadores y portales informativos o asociados a periódicos, señales de televisión y de radio, multiplicando las variables de competencia, ya que no sólo se compite con otros sitios informativos, sino también con otro tipo de entornos virtuales. Esto explica en parte el hecho de que muchas empresas periodísticas -fundamentalmente diarios- que habían optado inicialmente por el acceso gratuito a sus ediciones digitales, hoy estén migrando hacia alternativas de acceso pago (Díaz Nosty, 2013).

2 IPG Mediabrands (2017). Proyecciones publicitarias de Magna. Edición de invierno (4 de diciembre de 2017). [Informe]. Obtenido de https://bit.ly/2u4qUMr 
En cuanto al segundo punto, el nivel de penetración de internet es, en el caso de Argentina, muy importante: según datos oficiales, al primer trimestre de 2018 existen 8,037 millones de líneas de internet fija, y de cada 100 hogares argentinos 58,82 cuentan con ese servicio; al mismo tiempo, hay 61,7 líneas de comunicaciones móviles $^{3}$, por lo tanto en el país existen más de 139 líneas por cada 100 habitantes. La evolución de los accesos a internet es, además, significativa: las líneas de comunicaciones móviles crecieron un $28 \%$ en los últimos diez años ${ }^{4}$.

La enorme penetración que alcanzó internet no ha implicado, sin embargo, la caducidad de los medios tradicionales; al contrario, los estudios recientes muestran que en Argentina la televisión y la radio siguen siendo los medios más consumidos y los contenidos informativos se encuentran entre los más elegidos ${ }^{5}$. Al mismo tiempo, en los últimos años, un fenómeno se encuentra en crecimiento generando formas inéditas de uso y consumo de diversos productos culturales: la articulación entre pantallas, el consumo simultáneo de distintos tipos medios - muchas veces uno tradicional y uno digital-, y la articulación entre ambos consumos, por ejemplo respondiendo a las propuestas de interacción a través de la web que se hacen desde los medios tradicionales, o buscando más información sobre lo que se consume y/o comentándolo con otras personas vía redes sociales o servicios de mensajería instantáneos, entre otras posibilidades ${ }^{6}$.

Este consumo múltiple y simultáneo es uno de los fenómenos que Henry Jenkins (2008) definía hace ya unos años como parte de la "cultura de la convergencia", haciendo foco en las nuevas formas de socialización e interacción, más allá de los aspectos tecnológicos.

En cuanto a la tercera dimensión en la que se basan las conceptualizaciones en torno al nuevo ecosistema informativo, referida a las lógicas de producción, se trata precisamente de una de las transformaciones que nos proponemos explorar en este trabajo, a partir del análisis de un caso: la redacción del diario Día a Día de la ciudad de Córdoba. En efecto, nuestro objetivo es reconocer los impactos que ha tenido la expansión de las tecnologías digitales en la práctica del periodismo profesional, en el sentido de dar cuenta de los modos en que algunos aspectos fundamentales de la profesión se ven alterados a partir de la interacción de los medios tradicionales con los nuevos entornos digitales. Nos focalizaremos particularmente en dos cuestiones sustantivas: por un lado, en los modos de entender la noticia, definida clásicamente como ruptura o novedad; por otro, en la calidad e innovación del tratamiento infor-

\footnotetext{
Incluyen telefonía e internet móvil.
}

4 Ente Nacional de Comunicaciones (ENACOM) (2018). Indicadores de Mercado TIC, Postal y Audiovisual. 1er trimestre 2018, República Argentina. [Informe estadístico]. Obtenido de https://bit.ly/2tWiwyh

5 Según datos oficiales, un $70 \%$ de la población argentina escucha radio y los programas informativos son los segundos más escuchados luego de los contenidos musicales, aunque a partir de la franja de 30 años en adelante los primeros van ganando terreno hasta convertirse en los preferidos. Respecto a la televisión, la consume más del $95 \%$ de la población, y la mayoría lo hace a través del televisor. Fuente: Sistema de Información Cultural de la Argentina (SInCA) (2017). Encuesta Nacional de Consumos Culturales 2017. [Informe]. Obtenido de https:// bit.ly/2uF5fsd

6 Un estudio del Centro de Mediciones sobre Opinión Pública de la Universidad Nacional de Rosario indica que un $51 \%$ de los rosarinos consume televisión y en simultáneo utiliza un dispositivo conectado a internet a fin de interactuar con el contenido que están consumiendo en la pantalla principal. Fuente: Centro de Mediciones sobre Opinión Pública (CeMOP) (2017). Estudio cuantitativo sobre consumo de medios. Ciudad de Rosario, Argentina. [Informe]. Obtenido de https://bit.ly/2igDZw5

La ya citada encuesta del Sistema de Información Cultural de la Argentina (2017) señala que un 42,8\% de jóvenes entre 12 y 19 años publica en redes sociales comentarios sobre programas que mira en televisión. 
mativo, considerado un aspecto clave para la participación ciudadana y la vigencia de la democracia.

\section{Aspectos metodológicos y la elección del caso de análisis}

Día a día fue un diario creado en 2004 por la compañía Cimeco S.A. - una de las unidades de negocios del Grupo Clarín, propietaria también del diario La Voz del Interior ${ }^{7}$ y de otros medios de comunicación de Córdoba ${ }^{8}-$, con el fin de anticiparse al desarrollo de un posible competidor en el segmento de medios gráficos orientados a un público popular y de menor precio de tapa. El diario comenzó a editarse el 3 de mayo de ese año, inicialmente de lunes a viernes, luego se extendió a los fines de semana en 2007, para finalmente volver a una edición restringida de lunes a sábado en 2015.

En el año 2009 lanzó su portal de noticias diaadia.com.ar, y rápidamente logró un impacto importante entre los medios digitales de carácter local, en tanto llegó a tener una de las comunidades más numerosas en Facebook, alcanzando en diciembre de 2017 unos 780 mil seguidores, frente a los casi 930 mil de La Voz del Interior y los poco más de 850 mil de Cadena 3 , por ejemplo.

A partir del lanzamiento del portal, dos equipos de redacción coexistieron en Día a Día: por una parte, un grupo dedicado prioritariamente a la producción de la edición papel, pero con responsabilidades también en la producción para la edición digital; por otra, un equipo propiamente "digital" constituido sólo por tres personas, dedicado exclusivamente a la publicación de noticias y otros contenidos en la web, y a cierta interacción en redes sociales.

Luego de varios años de crecimiento sostenido en su posicionamiento en el entorno de los medios digitales cordobeses, tanto por su comunidad de seguidores en las redes (Facebook principalmente) como por el tráfico de visitas directas, en mayo de 2017 Día a Día se integró a Vía País, un nuevo proyecto del holding empresario Clarín que consistió en el desarrollo de una red nacional de portales informativos, con cabecera en la ciudad de Buenos Aires y nodos en distintas localidades del país, en la mayoría de los casos asentados sobre los equipos periodísticos de medios ya existentes. Así fue que diaadia.com.ar pasó a ser Día a Día+Vía País en viapais.com. ar/cordoba.

Pero eso no fue todo: a pesar del rediseño del diario papel lanzado en septiembre de 2017, en diciembre del mismo año, luego de más de cinco años de convivencia de las ediciones digital e impresa, la conducción de la empresa tomó la decisión de poner fin al diario en papel, manteniendo un pequeño equipo periodístico para continuar el nodo Córdoba de Vía País, y reubicando a la mayoría de los periodistas de Día a Día en la redacción de La Voz del Interior.

El cierre del diario no sólo afectó la pluralidad del sistema mediático cordobés y la situación laboral de los trabajadores, sino que constituye una evidencia significativa de que las transformaciones en la esfera de los medios de comunicación y del periodismo están en pleno desarrollo, y resulta difícil prever las direcciones en las cuales se orientarán en el futuro.

\footnotetext{
$7 \quad$ Es el diario de mayor circulación de la provincia de Córdoba, y actualmente el más antiguo. Junto a la emisora de radio Cadena 3, está entre los medios de mayor incidencia en la construcción de la agenda pública local.

8 Radio Mitre, FM Mía, Canal 12, etc.
} 
Los datos que se analizan en este trabajo ${ }^{9}$ provienen, por un lado, de las jornadas de observación etnográfica realizadas entre los meses de julio y octubre de 2017, tanto dentro de la redacción de Día a Día como en ciertos ámbitos públicos en los que algunos periodistas llevaron a cabo actividades de reporteo; y por otro, de una serie de entrevistas a periodistas del diario que tuvieron lugar mayoritariamente entre diciembre de 2017 y febrero de 2018.

Tanto el proceso de recolección de tales datos como su posterior análisis se llevaron a cabo siguiendo los planteos metodológicos generales de la perspectiva del newsmaking, en articulación y diálogo con los postulados de la sociología pragmática francesa que permiten, siguiendo a los actores, reconocer los imperativos de justificación que contextualizan su acción (Boltanski y Thevenot, 2006; Latour, 2008; Lemieux, 2000; entre otros).

\section{Resultados: ¿fin del periodismo industrial?}

Los clásicos estudios de gatekeeping y newsmaking desarrollados en el ámbito de la sociología de los medios de comunicación desde mediados del siglo XX permitieron, frente a las hipótesis ampliamente extendidas de los medios como mero reflejo objetivo de la realidad o como mera manipulación, revelar el verdadero proceso industrial de producción informativa que tiene lugar en ellos: una forma rutinizada de organización del trabajo periodístico que supone tres instancias o fases de recolección, selección o procesamiento y presentación de la información (Tuchman, 1983; López, 1995; Wolf, 2013, entre otros). Las cotidianas necesidades de producción informativa que devinieron de la industrialización de los medios masivos pusieron en evidencia que en la práctica diaria se recurre predominantemente a las oficinas de prensa y difusión de los organismos oficiales y a las agencias de noticias, y que las tres fases se estructuran a partir de una serie de criterios vinculados más al propio proceso productivo en sí -como la disponibilidad de fuentes, las condiciones y limitaciones establecidas por el formato (soporte, periodicidad, etc.), la configuración del sistema en virtud de los competidores, entre otros- que a partir de los criterios que tradicionalmente prescribió la doctrina liberal de la prensa en relación a su rol para la vigencia de la democracia.

Ahora bien, cabe preguntarse hasta qué punto el desarrollo de los nuevos entornos digitales, han transformado la lógica del proceso de producción que caracterizó al periodismo industrial.

En Día a Día, los dos equipos que -como ya hemos señalado- convivían en la redacción se organizaban en virtud de las formas y los tiempos que, desde su propia perspectiva, caracterizan al consumo de los medios tradicionales y de los medios digitales, así como el proceso de producción que impone el soporte en términos materiales (el diario papel en este caso) ${ }^{10}$. En ese sentido, la primera periodista en llegar

\footnotetext{
9 Los datos son parte de una investigación que se enfoca en las rutinas periodísticas en medios de comunicación cordobeses, en el marco de la convergencia digital y los debates en torno a la regulación mediática. Se trata de una indagación realizada como parte de nuestra formación doctoral en Ciencias Sociales en la Universidad de Buenos Aires (Argentina).

10 Presentamos aquí la lógica general de organización de Día a Día, identificada a lo largo del trabajo de campo en virtud de las observaciones etnográficas y las entrevistas. En adelante, al ejemplificar algún aspecto concreto se especifica la procedencia del dato en particular.
} 
a la redacción a las 7 de la mañana era una redactora del equipo digital, quien prontamente comenzaba a publicar en el portal noticias vinculadas al clima, producidas sobre la base de los partes oficiales de la Policía de la Provincia de Córdoba y la Fuerza Policial Antinarcóticos, y otras noticias "calientes" de la mañana, mientras que los periodistas de la redacción impresa comenzaban a llegar a partir de las 9 o 10 horas, o después del mediodía, dependiendo de su turno de trabajo (mañana o tarde). Durante la siesta estaban casi todos para la realización de las reuniones de sección y "de blanco", en las cuales se definían los lineamientos principales de la edición papel del día siguiente, y se ponían en común las propuestas y avances de las coberturas especiales destinadas fundamentalmente a las ediciones de los días sábados y lunes. El equipo digital se completaba con la llegada de su editora cerca del mediodía, y la llegada del otro redactor a partir de las 16 horas, quien se concentraba más en la interacción en redes sociales, en subir al portal la edición impresa al cierre, y en dejar programada la publicación o republicación de algunas notas para el día siguiente, finalizando su horario a la medianoche. Un eje transversal del trabajo del equipo digital era la publicación en la web de noticias "blandas" o "clickeras", pero esta tarea se desarrollaba con más intensidad durante la tarde.

Esta forma de organización del trabajo y de los turnos estaba vinculada al horario aproximado de cierre de la edición impresa (entre las 22 y las 23), y al horario en que se concentraba el mayor volumen de tráfico y de consumo de noticias en internet (durante la primera mañana y hasta el mediodía), algo que podía constatarse en la cifra que permanentemente mostraba una pantalla sobre una de las paredes de la redacción con la medición en tiempo real de la cantidad de usuarios activos en la red Vía País, así como un ranking de las noticias más "clickeadas", entre otros datos ${ }^{11}$.

A pesar de esta diferenciación entre los equipos, los periodistas de la redacción impresa publicaban a lo largo de su jornada laboral algunas notas en la web, como anticipo de las temáticas que trabajarían para la edición impresa, o bien abordando las noticias "calientes" que se iban produciendo en el día a partir de alguna declaración de un funcionario, alguna novedad judicial o policial, alguna manifestación callejera, etc. Más aún, se esperaba que esos periodistas publicaran en promedio 2.5 notas en la web por día, según lo explicita el Director Periodístico: "La persona viene. Se da por sentado (salvo los tres que son digitales puros), que viene a trabajar para el diario de papel, pero también que tiene que hacer dos notas y media por día en digital de promedio al mes, porque nuestra atención es que pasen cosas a la web" (entrevista).

Este es el lineamiento que se planteó en 2015 a los trabajadores de la redacción papel, en relación con la decisión de fortalecer y dar mayor preponderancia al soporte digital, reduciendo también la cantidad de ediciones papel de siete a seis por semana. Como parte de este lineamiento, se definió también anticipar toda la producción periodística en el portal on line, aunque hasta el cierre del diario esa definición continuó siendo objeto de discusiones en la redacción: "Nosotros decidimos anticipar todo, o sea, son pocos los temas que están en el diario de papel de mañana que no han sido ya dados a lo largo de esta tarde o de esta noche, cuando el diario se está cerrando (...). Nuestro desafío es poder entender que los públicos son bastante diferentes y poder fortalecer lo más posible nuestra performance digital. Nosotros elegimos ese camino" (Director Periodístico, entrevista); "Fue cambiando mucho en los

11 La herramienta utilizada para esta medición era Google Analytics. 
años, sobre todo qué publicar en papel y qué en web, pero en los últimos dos años creo que primó el "digital first", que es olvidarse de que hay que guardar algo... Si bien siempre fue un tema de conversación porque algunos editores del papel eran muy reacios a tirar algunas cosas en la web primero, pero fue cambiando y creo que se fueron dando cuenta de que en tiempos digitales no existe la primicia como "el primero que la tira", sino que el valor de la primicia tiene más que ver con el tratamiento, el análisis, o el descubrimiento de un lado distinto de la noticia" (Editora del equipo digital, entrevista).

Pero ¿es lo mismo producir noticias para un diario en papel que hacerlo para un portal de noticias on line? La experiencia que hemos relevado en Día a Día a partir de nuestras observaciones indica que no, y que de hecho los criterios de noticiabilidad que predominan para un soporte y para el otro, así como el tratamiento de la información, son en algunos aspectos distintos.

Para empezar, en general Día a Día, por su propio perfil de diario popular, priorizó históricamente las noticias de carácter local frente a las nacionales o internacionales, pero con su integración a Vía País la producción de las notas para la web correspondientes a hechos ocurridos fuera de Córdoba quedaron exclusivamente bajo la órbita del equipo de redacción de la cabecera (asentada en la ciudad de Buenos Aires) o para el nodo en el que esos hechos hubieran ocurrido (Rosario, Mendoza, etc.). También se reservó a la cabecera la decisión acerca de qué noticias de las producidas en toda la red jerarquizar en la página de inicio de cada nodo y la facultad de indicar a cualquiera de estos nodos la publicación de una cierta nota en sus redes sociales. A propósito de este punto, en una jornada de observación la redactora del equipo digital explica que mediante un software de mensajería grupal denominado Slack los editores de Buenos Aires le indicaban las noticias que debía subir a las redes en carácter de "prioridad" o "sugerencia" -las primeras, en principio debían ser publicadas obligatoriamente, mientras que con las "sugeridas" tenía algún margen para decidir en qué momento hacerlo-. La redactora comenta que en general las notas que le solicitaban publicar durante la mañana como "prioridad" eran las "virales", y que eso había producido "un conflicto de intereses" entre las políticas editoriales de Día a Día y de la cabecera de Vía País, porque "nosotros somos los que conocemos a nuestra comunidad", y por lo tanto podían anticipar que la publicación de un cierto tipo de notas a las 9 de la mañana en Facebook generaba una reacción adversa en los usuarios; como explica la redactora: "yo no puedo publicar una nota de Laura ${ }^{12}$ sobre un femicidio, con información sobre estadísticas de femicidios en Córdoba, visibilizando la problemática", y a continuación subir "una viral de las cinco mejores fotos del culo de Sol Pérez ${ }^{13}$ " que indicada como "prioridad" desde la cabecera (diario de campo, 01/08/2017). En cambio, para la edición impresa, la producción de noticias de carácter nacional e internacional, así como su jerarquización editorial, siguió siendo tarea y decisión de los periodistas de Día a Día.

Este tipo de conflictos en términos de política editorial también se expresó en una situación concreta en torno a la publicación, desde la cabecera de Vía País, de una nota con imágenes del cadáver aparecido el 17 de octubre de 2017 a orillas del Río

12 Redactora del equipo de edición impresa, habitualmente encargada del seguimiento de noticias vinculadas a cuestiones de género, violencias hacia las mujeres, etc.

13 Personaje del mundo del espectáculo televisivo argentino. 
Chubut y que más tarde se confirmó que correspondía a Santiago Maldonado ${ }^{14}$. Uno de los redactores del diario comenta al respecto en una de las jornadas de observación que esa nota se publicó en la página de inicio del sitio y en la página de Facebook de Día a Día por acción de un software de posteo automático de noticias implementado en el mes de octubre en la redacción ${ }^{15}$. La difusión de las imágenes generó una reacción muy negativa de los usuarios de la red social, al punto de que requirió la intervención del Jefe de Información y del Director Periodístico del diario para que la cabecera de Vía País aceptara eliminar esa publicación (diario de campo, 24/10/2017). Al respecto, la redactora del equipo digital también comenta: "Si, fue un caos. Fue un problema editorial muy grande ahí, de hecho hubo peleas entre editores. Peleas en el buen sentido, en el sentido de diferencias de criterios. Hay que priorizar, no es más importante un click que el sentido editorial del diario. Pero bueno, desde Buenos Aires tenían la urgencia de ser los primeros en publicarlo, y resultó ser que no sólo fuimos los primeros, sino que fuimos los únicos, nadie más publicó eso, porque era impublicable. Lo bueno de que se implementara esa herramienta fue que yo no tenía que estar pendiente de estar publicando cada quince minutos en Facebook, pero las primeras veces tenía que estar pendiente de lo que publicaba, porque se movía por variables de lo que más estaba buscando la gente (...). Para ser un robot, era una máquina, pero bueno, estaba sujeto a errores, igual que los humanos" (entrevista).

Por otro lado, el criterio establecido desde la cabecera de Vía País fue publicar las "breaking news", es decir, las noticias de último momento, aun cuando no se tuviera mucha información, subiendo al menos un título y una bajada, y luego completando la nota a medida que se consiguieran más datos. En ese sentido, durante las jornadas de observación, percibimos que en el transcurso de la mañana frecuentemente se subían a la web noticias construidas sobre la base de información publicada por otros medios como única fuente. Esto suponía que para la producción de noticias en el entorno digital no había tiempo ni recursos para trabajar con fuentes propias o no era importante hacerlo, ni siquiera para chequear la información que se publicaba, sino que la sola difusión de esa información por parte de ciertos medios era suficiente para otorgarle verosimilitud a la noticia y reproducirla.

Sin embargo, esta forma de construcción periodística de la información, sin chequeo y sin consulta a fuentes propias, no se daba con todos los hechos ni con todos los temas. En una jornada observamos que uno de los periodistas de la redacción papel comenta a viva voz que se había publicado en el portal web Villa María Vivo la noticia de que se había hallado el cadáver de una niña en la localidad de Tío Pu$\mathrm{jio}^{16}$. La redactora del equipo digital toma la tarea de producir una nota para la web, y llama a la oficina de Prensa de la Policía de Córdoba para obtener más datos; ante la respuesta negativa del organismo de seguridad, el Director Periodístico le sugiere

14 Se trata de un joven argentino cuya desaparición se produjo el 1 de agosto de 2017 en el marco de la acción represiva de una fuerza de seguridad nacional (Gendarmería) sobre un corte de ruta realizado por integrantes de una comunidad mapuche en resistencia en el sur del país. La desaparición de Maldonado motivó una fuerte crisis política, debido al accionar del Poder Ejecutivo nacional y de los funcionarios judiciales intervinientes en la investigación. Dos meses después, el cadáver del joven fue hallado muy cerca del lugar donde había sido visto por última vez con vida.

15 Ecobox: un software que postea automáticamente ciertas notas publicadas en la web en las redes sociales, en virtud de diversas variables.

16 Una pequeña localidad ubicada a unos 135 kilómetros al sureste de la ciudad de Córdoba. 
que busque en internet el teléfono de alguna comisaría de la localidad, pero tampoco logra comunicarse al número que encuentra; decide consultar otros medios digitales para ver si se han publicado algo al respecto y encuentra que donde la información aparece, no se menciona ninguna fuente concreta sino "fuentes oficiales", por lo que deja la nota lista pero sin publicar hasta contar con algún chequeo. Luego de unos minutos el Director Periodístico le pasa dos contactos que le ha facilitado un redactor de Policiales que no se encuentra en ese momento en la redacción (el de una fiscal que estaría interviniendo en el hecho y el de un comisario), pero le anticipa que la noticia ya está en lavoz.com.ar ${ }^{17}$, y le indica que suba un "alerta" al sitio, pero sin publicarlo en Facebook aún. Finalmente, la redactora logra comunicarse con el comisario antes de subir la nota a la web, chequeando la información con una fuente oficial (diario de campo, 19/07/2017).

Estas diferencias en el tratamiento periodístico de los hechos se deben, por un lado a que sólo algunos medios de comunicación son considerados lo suficientemente confiables como para constituirse en la única fuente de una noticia -la información del portal Villa María Vivo debe ser chequeada, pero la que publica La Voz del Interior no lo requiere-; y por otro al tópico en torno a la cual se está informando: un hecho policial que involucra el fallecimiento de una niña debe ser tratado con más cuidado y rigurosidad que otros hechos policiales, y que otros hechos del orden político, económico o cultural.

Precisamente, en lo que refiere a hechos de tales órdenes -clásicamente definidos en el ámbito del periodismo profesional-, lo que se observamos a partir de nuestro trabajo etnográfico es que las formas de construcción de noticias correspondientes a esos tópicos respondían muy frecuentemente a pautas estandarizadas e históricamente rutinizadas de la producción informativa. Por ejemplo, una nota referida a los créditos que la Agencia Nacional de Seguridad Social lanzó en 2017 para jubilados que cobran el haber mínimo, beneficiarios de la Asignación Universal por Hijo y otros programas sociales, surge de un dato oficial sobre la cantidad de créditos solicitados durante los primeros meses desde su puesta en vigencia, y a pesar de que en la reunión de sección se conversa sobre los posibles y diversos abordajes críticos del dato, con el fin de darle una "fácil resolución" a la elaboración de la nota se decide tomar sólo el dato oficial, sin complejizarlo, ni proponer otros interrogantes que tiendan a darle protagonismo a otros actores o a posibilitar otros criterios de contextualización (diario de campo, 17/07/2017).

La vigencia de esas pautas rutinizadas y estandarizadas en el tratamiento periodístico de los hechos se constata también en que -más allá de las transformaciones que implican las innovaciones tecnológicas- no observamos que Día a Día desarrollara estrategias que permitieran la expresión de la audiencia sobre la cobertura que el diario ofrecía, sobre sus necesidades e intereses informativos, ni tampoco era productora de información. Al respecto, en una jornada de observación, uno de los editores plantea al observar la interacción de los usuarios en Facebook sobre una nota referida a un anuncio del Gobernador Schiaretti ${ }^{18}$-principalmente comentarios con insultos contra el funcionario- que las redes sociales se prestan mucho para el agravio, en lugar de ser un ámbito de expresión o intercambio de información (diario de campo, 24/07/2017).

Portal de noticias del diario La Voz del Interior, que ya hemos mencionado.

Gobernador de la Provincia de Córdoba desde 2015 y hasta 2019. 
Por otro lado, en los casos en los que la audiencia se constituye en fuente de una cierta información, los criterios de noticiabilidad con los que operan los periodistas son aquellos que han articulado tradicionalmente la lógica de la producción informativa, dejando al lector o usuario simplemente en ese rol de fuente sin ningún otro tipo de intervención en la construcción editorial de la noticia. Lo relevante en este punto es que las audiencias de los medios históricamente y con mucha frecuencia se han convertido en fuentes, sobre todo en lo que refiere a ciertos tópicos, como el de policiales. A modo de ejemplo, citamos una anécdota compartida por un redactor precisamente de la sección Policiales, quien en una ocasión recibió a través del inbox de la página de Facebook del diario un mensaje que posteriormente dio lugar a una cobertura: "cuando murió Pablo Rielo (el rosarino que murió en una fiesta electrónica), me escribe una naranjita ${ }^{19}$ al inbox del diario, diciendo "yo vi todo, yo lo asistí y estuve con él. Quería saber si estaba vivo o si había fallecido". En ese momento todavía estaba grave. Yo le respondo, ella me pasa un teléfono, la llamo y me cuenta todo. Fue un testimonio único todo ese lunes, ya después el martes lo levantaron otros medios, donde ella cuenta que estaba cuidando autos, que lo encuentra, que se queda una hora con él, que llama dos veces a la ambulancia, la ambulancia no viene y el chico se le empieza a morir en brazos. Un testimonio larguísimo y ese testimonio llegó a la justicia, y la citan a declarar. Por eso es muy valioso llevarle el apunte a las redes sociales" (entrevista). En este ejemplo, más allá de que la información sobre el hecho hubiera llegado al diario a través de esta usuaria de la red social, su participación en el proceso de producción de la noticia fue sencillamente en el rol de fuente testimonial, algo que es muy habitual en la elaboración de noticias policiales, sin que ello implique una innovación o transformación de las lógicas de construcción periodística o en los criterios de noticiabilidad tradicionales.

El uso de medios digitales en las mismas prácticas en las que hace unos años se utilizaban sistemas de comunicación analógicos -como el teléfono fijo- no supone necesariamente nuevas formas de interacción entre periodistas y audiencias. Más aún, esa interacción -concebida en el sentido de incidir sobre la lógica de la producción informativa - tenía en Día a Día un impacto muy específico: en la construcción editorial del portal operaba una distinción importante entre las "noticias" por un lado, y los "contenidos" por otro, que eran los que mayoritariamente generaban "respuesta" por parte de la audiencia. Como indica una periodista al respecto: "Siempre Día a Día tuvo una característica más blanda respecto a otros medios de comunicación de noticias de Córdoba. Si bien llevábamos el minuto a minuto del breaking news, también teníamos mucha presencia de noticias que tienen que ver con los servicios o temas útiles para la audiencia, y también temas que la lleven al entretenimiento o a lo que se denomina el "lifestyle", o temas más relacionados a la vida cotidiana, a la salud, la gastronomía. Son los focos que tuvimos siempre, un poco equilibrando la balanza entre noticias y ese tipo de contenidos. Porque si bien sabíamos que las noticias son importantes, este otro foco también es muy fuerte para la atención de los usuarios, entonces es un contenido que vale la pena hacer porque tiene una buena respuesta" (Editora del equipo digital, entrevista).

19 Se refiere a las personas que trabajan en el cuidado de vehículos en la vía pública en los lugares en los que el estacionamiento no está controlado, o en los horarios en los que no es pago, según las disposiciones normativas del Municipio. El caso refiere a la muerte de un joven que falleció, según la investigación judicial, producto del consumo problemático de sustancias y de una mala atención de salud recibida en el lugar en el que se desarrollaba la fiesta a la que había asistido. 
A lo largo de nuestras jornadas de trabajo de campo en la redacción de Día a Día lo que observamos fue, en este sentido y como ya hemos indicado, la vigencia de una lógica sumamente tradicional en el proceso de producción informativa.

\section{A modo de cierre: ¿un nuevo ecosistema informativo en Córdoba?}

Los datos recogidos a partir de nuestra investigación confirman algunos de los planteos que desde el ámbito académico se han realizado en los últimos años en torno a la emergencia de un nuevo ecosistema mediático, en lo que refiere a los modos de informar:

- Asistimos hoy en los medios digitales a una suerte de "edición continua" y a un desplazamiento del concepto de noticia, definido clásicamente como ruptura o novedad, hacia "contenidos informativos", en los que un acontecimiento puede volverse noticiable aunque no provoque o haya provocado ninguna disrupción, así como un desplazamiento del valor "verdad" al valor "verosimilitud", en tanto cada vez con mayor frecuencia una información logra instalarse y difundirse como noticia sin haber sido debidamente chequeada y corroborada (Díaz Nosty, 2013: XV; Luchessi, 2013: 119-121).

- A su vez, estas transformaciones están relacionadas con las presiones a las que se enfrentan los periodistas para publicar información al instante sin el debido chequeo y contrastación de fuentes-, exponiéndolos difundir ciertas noticias para no quedar al margen del flujo informativo y perder legitimidad ante la audiencia (Luchessi, 2013; Salaverría y Negredo, 2008).

- La prescripción de sostener el ritmo del flujo informativo ha expandido la importancia en la prensa mundial, y particularmente en los medios latinoamericanos, del denominado periodismo "declaracionista" (Lichfield, 2000; Guerrero y Márquez-Ramirez, 2014), consistente en convertir en noticiable las declaraciones de una figura del ámbito público, más allá de que haya novedad o no en ellas y por supuesto sin ningún tipo de chequeo, en un contexto de altísima conflictividad y polarización en términos políticos: la noticia no son los fenómenos o problemáticas a los cuales los dichos de una persona pública se refieren, sino las propias declaraciones, que a su vez darán lugar a una nueva noticia a través de la réplica o los comentarios de otra figura pública, alimentando esa lógica.

- La publicación de noticias cuya única fuente son los medios considerados confiables refuerza la homogeneización, el "clonado" de agendas (Díaz Nosty, 2013: 134): frente a la promesa de los entornos digitales de diversificar y multiplicar la información disponible, lo que se produce es una enorme redundancia y convergencia de noticias y temáticas, incluso en portales informativos que se supone que compiten entre sí. Y más aún, como ocurre desde hace décadas, los medios más consagrados, con mayores recursos y mejor acceso a fuentes, terminan marcando el devenir del flujo informativo al publicar noticias que otros medios simplemente reproducen.

Esta es la tendencia principal, aun cuando el desarrollo de las tecnologías digitales haya facilitado el surgimiento de nuevos medios, o el acceso a otro tipo de infor- 
mación, a información de mayor calidad (Boczkowski, 2006; entre otros), e incluso a información que -recurriendo a otras fuentes documentales, institucionales o testimoniales- contrastan o desmienten la mirada sobre la actualidad que los medios de comunicación consagrados construyen.

Pero al mismo tiempo, los datos de nuestra investigación suponen un contrapunto con otros planteos vinculados al concepto de ecosistema informativo: fundamentalmente aquellos que indican que los usuarios y usuarias, las audiencias, han ganado una incidencia inédita en el proceso de producción de las noticias. En efecto, desde algunos trabajos académicos se sostiene que las audiencias "se han convertido en polos de irradiación informativa" que configuran un "ágora abierta, donde todos hablan a todos" (Díaz Nosty, 2013: 54), en la cual el periodista se ha constituido en una suerte de "curador" que selecciona y legitima la información que produce la audiencia en red (Rincón, 2013: 17-18). Son también las propuestas conceptuales que afirman que los consumidores han devenido "prosumidores" (Islas Carmona, 2008; García Canclini, 2011; entre otros), en tanto la distancia que introdujo la lógica industrial entre la instancia de la producción y la instancia del consumo se desdibuja a partir de las posibilidades que ofrece la web 2.0 (y sus versiones posteriores) y las tecnologías digitales y móviles para crear y difundir masivamente contenidos.

Sin embargo, la mera existencia de tales herramientas no supone por sí misma la mayor distribución del poder de expresión y del acceso a información significativa que la democracia electrónica ha prometido: poner atención a la respuesta que en términos cuantitativos los usuarios producen frente a la publicación de una noticia en una red social está más cerca de la lógica mercantil que atraviesa hoy a los entornos digitales que de la tan mentada democratización de las comunicaciones.

Los medios masivos, ya sea a través de sus soportes tradicionales o bien de sus entornos digitales, siguen concentrando en buena medida la capacidad de legitimar o deslegitimar, visibilizar o invisibilizar, no sólo tópicos, hechos y fuentes, sino también procesos históricos que los contextualizan, actores sociales, y formas de expresión pública.

Esto no significa que en los últimos años, de la mano de importantes luchas ciudadanas, no se hayan multiplicado las voces y ampliado los límites de la esfera pública, y que las nuevas tecnologías no hayan tenido un rol importante en ese proceso. Pero las transformaciones a las que hemos aludido a lo largo de este trabajo en el marco del desarrollo de un nuevo ecosistema informativo, no sólo no suprimen los numerosos problemas a los que se enfrentan las democracias contemporáneas, sino que plantea nuevos y sustanciales desafíos para su vigencia y ampliación. Queda aún mucho camino que recorrer en el proceso de universalización de los derechos a la comunicación y de construcción de democracias abiertas y sustantivas, en las que los ciudadanos sean los protagonistas de la definición del tipo de sociedad en el que pretenden vivir.

\section{Referencias bibliográficas}

Aguado, J. M. \& Martinez, I. (2008): "La comunicación móvil en el ecosistema informativo: de las alertas SMS al Mobile 2.0". Trípodos, 23, pp. 107-118. Obtenido de https:/core. ac.uk/download/pdf/39028976.pdf 
Almirón, N. \& Segovia, A. (2012): "Financialization, Economic Crisis, and Corporate Strategies in Top Media Companies: The Case of Grupo Prisa". International Journal of Communication, 6, pp. 2894-2917. Obtenido de https://eprints.ucm.es/35876/1/IJOC-Almiron\%26Segovia.pdf

Boczkowski, P. (2006): Digitalizar las noticias. Innovación en los diarios on line. Buenos Aires: Manantial.

Boltanski, L. \& Thevenot, L. (2006): On justification. Nueva Jersey: Princeton University Press.

Campos Freire, F. (2011): "Las empresas de medios de comunicación revisan y amplían sus modelos de negocio". Razón y Palabra, 74, pp. 1-25. Obtenido de http://www.razonypalabra.org.mx/N/N74/VARIA74/16FreireV74.pdf

Canavilhas, J. (2012): “Contenidos periodísticos en el ecosistema líquido: Entre la convergencia y la divergencia”. En F. Irigaray, D. Ceballos \& M. Manna (Eds.): Webperiodismo en un ecosistema líquido. Rosario: Laborde, pp. 11-24. Obtenido de https://rephip.unr. edu.ar/xmlui/handle/2133/2315

Díaz Nosty, B. (2013): La prensa en el nuevo ecosistema informativo. "iQue paren las rotativas!”. La transición al medio continuo. Madrid: Ariel. Obtenido de http://boletines. prisadigital.com/la_prensa_en_el_nuevo_ecosistema_informativo.pdf

García Canclini, N. (2011): "Comunicación y ciencias sociales: el giro transdisciplinario y la política”. Oficios Terrestres, 27 (I), pp. 1-19. Obtenido de http://sedici.unlp.edu.ar/bitstream/handle/10915/33000/Documento_completo.pdf?sequence=1\&isAllowed=y

Guerrero, M. \& Marquez-Ramirez, M. (2014): "The "captured liberal" model: media systems, journalism and communication policies in Latin America". The International Journal of Hispanic Media, 7, pp. 1-12. Obtenido de https://www.researchgate.net/publication/266080293_The_Captured-Liberal_Model_Media_Systems_Journalism_and_Communication_Policies_in_Latin_America

Islas Carmona, O. (2008): "El prosumidor. El actor comunicativo de la sociedad de la ubicuidad". Palabra Clave, 1 (11), pp. 29-39. Obtenido de http://palabraclave.unisabana.edu.co/ index.php/palabraclave/article/view/1413

Jenkins, H. (2008): Convergence Culture. La cultura de la convergencia de los medios de comunicación. Barcelona: Paidós.

Latour, B. (2008): Reemsamblar lo social: una introducción a la teoría del actor-red. Buenos Aires: Manatial.

Lemieux, C. (2000): Mauvaise presse. Una sociologie compréhensive du travail journalistique et de ses critiques. Paris: Métailié.

Lichfield, G. (2000): “La declarocracia en la prensa”. Letras Libres, 19. Obtenido de https:// www.letraslibres.com/mexico/la-declarocracia-en-la-prensa

Limia Fernandez, M., Lopez Garcia, X. \& Pereira Fariña, X. (2010): “15 años de cibermedios en España”. En X. Lopez Garcia \& X. Pereira Fariña (Coords.), Convergencia digital. Reconfiguración de los medios de comunicación en España. Santiago de Compostela: Universidad de Santiago de Compostela, pp. 9-25.

Lopez, M. (1995): Cómo se fabrican las noticias. Fuentes, selección y planificación. Barcelona: Paidós.

Luchessi, L. (2013): “¿Noticia o contenidos? Esa es la cuestión”. En L. Luchessi (coord.), Calidad informativa. Escenarios de poscrisis. Buenos Aires: La Crujía, pp. 113-127.

Rincón, O. (2013): “El periodista DJ es el medio". En L. Luchessi, (coord.): Calidad informativa. Escenarios de poscrisis. Buenos Aires: La Crujía, pp. 9-31.

Salaverría, R. \& Negredo, S. (2008): Periodismo integrado. Convergencia de medios y reorganización de redacciones. Barcelona: Sol 90. Obtenido de https://www.researchgate. 
net/publication/268810171_Periodismo_integrado_convergencia_de_medios_y_reorganizacion de redacciones

Tuchman, G. (1983): La producción de la noticia. Estudio sobre la construcción de la realidad social. México: G. Gili.

Wolf, M. (2013): La investigación de la comunicación de masas. Crítica y perspectivas. Buenos Aires: Paidós. 